\title{
Diagnostic Delay in Clinical Practice - A Case Report of Coeliac Disease
}

\author{
Ahmedul Kabir ${ }^{1}$, Sudip Ranjan Deb², Ruma Akhter, Mamunur Rashid Bhuyian ${ }^{3}$, Pratyay Hasan \\ 'Assuciate Professor, Department of Medicine, Dhaka Medical College, Dhaka, ${ }^{2}$ Assistant Prolessor. Department of Medicine. Dhaka Medical College, Dhaka, ${ }^{3}$ Medical Onicer, Depátment of \\ Medicinc, Dhaka Medical College. Dhaka
}

\begin{abstract}
:
Once considered a gastrointestinal disease of childhood affecting mainly whites, Coeliac Disease is now recognized as a systemic disease that may affect persons of any age and many races and ethnic groups. In this paper we present a case of a 60-year-old woman presented with protein-losing enteropathy associated with partial villous atrophy on distal duodenal biopsy. In Coeliac enteropathy the changes in intestinal permeability is sufficient to cause excessive loss of protein into the gut leading to hypoproteinaemia. The patient had presented with peripheral oedema without liver or renal impairment. The case emphasizes that clinicians should have a heightened suspicion about the disease that may be present at any age in both sexes and in a wide variety of clinical circumstances.
\end{abstract}

Keywords: Coeliac Disease, Villous atrophy, Diagnostic delay

[BSMMU J $2014 ; 7$ (1) : 68-70]

\section{Introduction:}

Coeliac disease is a systemic immune-mediated disorder triggered by dietary gluten in genetically susceptible persons. Gluten is a protein complex found in wheat, rye and barlcy. Cocliac Disease is characterised by a broad range of clinical presentations, a specific scrum autoantibody response and variable damage to the small-intestinal mucosa. 'The frequency of the disease is increasing in many developing countries because of westernization of the diet, changes in wheat cosumption and increased awareness of the disease. ${ }^{2}$

Its prevalence is 1.5 to 2 times as high among women as among men and is increased among persons who have an affected first degree relative (10 to $15 \%$ ), type-1 diabetes ( 3 to $16 \%$ ), Hashimoto's thyroiditis $(5 \%)$ or other autoimmune diseases (including autoimmune liver diseases, Sjogren's syndrome, IgA nephropathy), Down syndrome $(5 \%)$, Turner's syndrome (3\%), and IgA deficiency $(9 \%){ }^{2}$ Genetic background plays a key role in the predisposition to the discase. All patients with Coeliac Disease express HLA-DQ2, HLA-DQ8 allele. Though only a minority

Address for Correspondence: 1) Ahmedul Kabir, FCPS (Medicine), Deparment of Medicine, Dhaka Medcial College Hospital, Dhaka,

Telephone: +8801720910541, E-mail: ahmedul_986@yahoo.com expressing DQ2/DQ8 has Coeliac Disease but absence of DQ2iDQ8 excludes the diagnosis. ${ }^{3}$

\section{Case Report:}

In August, 2013, a 60-year-old woman presented to us with a 3-month history of swelling of both legs, fatigability, significant loss of weight and appetite. She had also experienced several episodes of loose stool along with cramping abdominal pain three years ago which had lasted for two months, 5-6 times in a day, voluminous, semisolid, not mixed with blood or mucous. After that she visited many physicians and her condition improved with general supportive measures. She had arthritis on both knee joints described as swelling, redness, raised temperature and painful movement. This had also been treated with intra articular steroid six month back. She had no significant family history. She was hypertensive and her blood pressure was controlled by losartan potassium and hydrochlorothiazide. She was non-diabetic. On initial assessment her pulse was 80 beats/min, blood pressure was $120 / 80 \mathrm{mmHg}$, temperature was normal, non-anaemic and non-icteric, a painless ulcer over the tongue, bilateral pitting ankle oedema extending to legs and lymph nodes were not enlarged. Examination of abdomen showed hepatomegaly, $5 \mathrm{~cm}$ below the costal 
margin along the mid-clavicular line, firm in consistency, margin rounded, smooth surface, no bruit, upper border of liver dullness present on the right fifth intercostal space at the mid-clavicular line, no splenomegaly and no ascites. Examination of other systems was unremarkable as well.

Complete blood count and urine routine microscopic examination and random blood sugar all were within normal range. 24 hours urinary total protein showed, urinary total volume: $1,750 \mathrm{ml} /$ day, urinary total protein: $0.21 \mathrm{gm} /$ day $(0.05-0.08 \mathrm{gm} /$ day $)$, serum albumin: $28 \mathrm{~g} / \mathrm{L}$ (35-50), S. creatinine: $111 \mu \mathrm{mol} / \mathrm{L}$, USG of whole abdomen revealed that liver is mildly enlarged with homogeneous echopattern. Chest X-ray (P/A) view and colonoscopy were normal. Endoscopy of upper GIT and tissue from duodenum for Histopathology showed: sections of duodenal

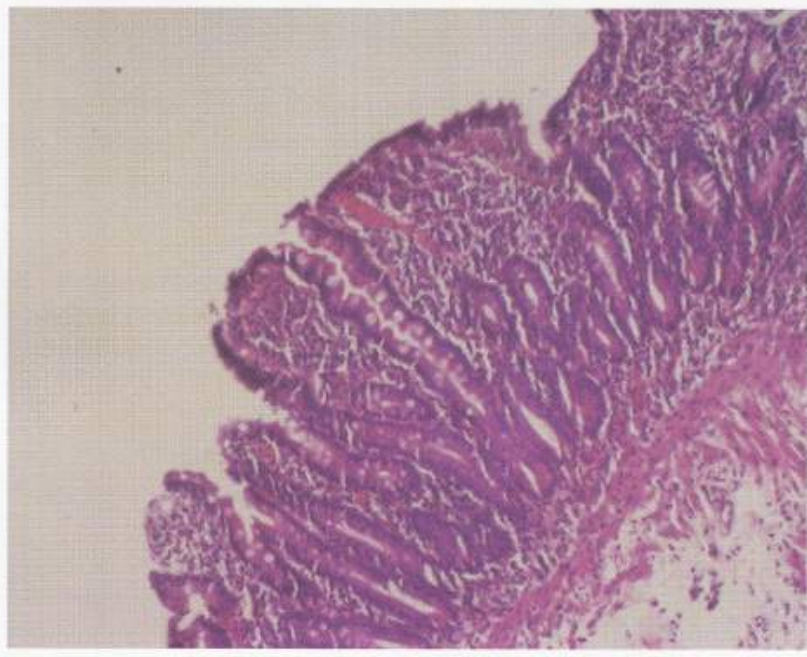

Fig-1: Biopsy taken from proximal duodenum showing partial villous atrophy with increased intraepithelial lymphocytes and inflammatory infiltrate in the lamina propria.

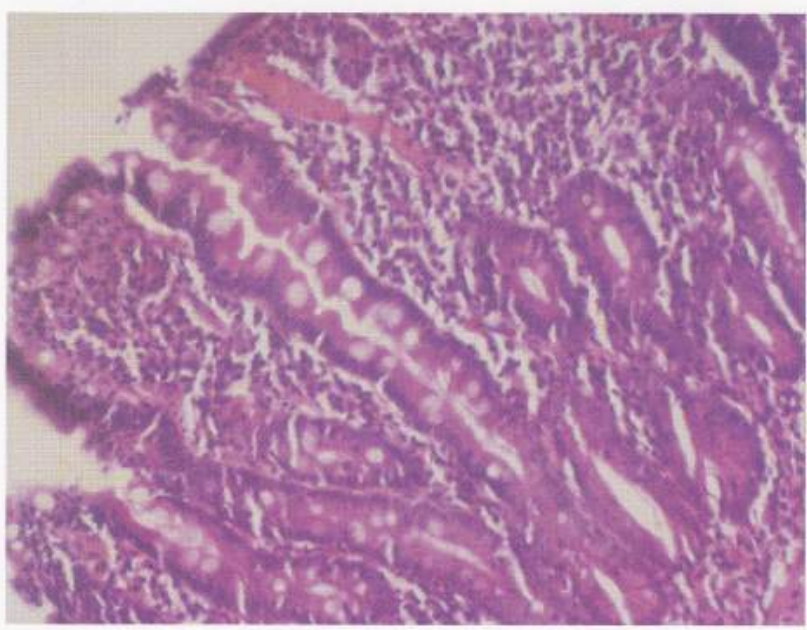

Fig-2: Biopsy taken from the same site (proximal duodenum) in an enlarged view showing elongated crypt. mucosa with slightly short villi and elongated crypts. Intra epithelial lymphocytes are increased $(>30 / 100$ enterocytes).The lamina propria contains many plasma cells, lymphocytes and small number of eosinophils. No malignant cells. Diagnosis was chronic duodenitis with partial villous atrophy. Tissue transglutaminase (tTG), IgA: $126.5 \mathrm{U} / \mathrm{ml}$ (Normal is upto $50 \mathrm{U} / \mathrm{ml}$ ). In the light of available history, clinical and histopathological findings, and the presence of serological markers an uncommon diagnosis of coeliac disease was considered.

\section{Discussion:}

Coeliac Disease is a permanent dietary disorder caused by an immunologic response to gluten, a storage protein found in certain grains that results in diffuse damage to the proximal small intestinal mucosa with malabsorption of nutrients. ${ }^{4}$ The aetiology of Coeliac disease is not known but environmental, immunologic and genetic factors appear to contribute to the disease. ${ }^{3}$ Gluten is a protein found in wheat, rye and barley. After being taken up by epithelial cells, gluten peptides are deamidated by the enzyme tissue transglutaminase in the subepithelial layer. They are then able to fit the antigen-binding motif on HLA-DQ2 positive antigen presenting cells. Recognition by CD4+ T cells triggers a Th1 immune response with generation of pro-inflammatory cytokines $\left(\mathrm{L}_{1}, \mathrm{INF}-\mathrm{y}\right.$ and $\mathrm{TNF}-\alpha$ ). Lymphocytes infiltrate the lamina propria and increased intraepithelial lymphocytes (IEL), crypt hyperplasia and villous atrophy ensue. ${ }^{5}$ The villi become inflamed and flattened. The surface area available for digestion is therefore decreased and a person is unable to absorb nutrients from food effectively.

In adults, damage to the small intestine may be severe without symptoms being obvious or specific. This may make it difficult for Coeliac Disease to be identified. Manifestations of Coeliac Disease include-diarrhoea, weight loss, steatorrhea, anaemia, folate, vit- $\mathrm{B}_{12}$ deficiencies, fatigue and generalized weakness, calcium, edema due to low albumin, failure to thrive in infants. ${ }^{6}$ When clinicians request serology, laboratories should use IgA tissue transglutaminase (tTG) as the first choice test. Intestinal biopsy in needed to confirm or exclude Coeliac disease to people with positive serological results from 
any tTG or EMA test.? Presence of IgA endomysial antibody and IgA tTG antibody tests both have $\geq 95 \%$ specificity and $\geq 90 \%$ sensitivity for the diagnosis. ${ }^{4}$ The finding of circulating IgA antibodies at the time of diagnosis and their disappearance following a gluten free diet added weight to the diagnosis. ${ }^{8}$ The ESPGAN recently proposed new criteria for the diagnosis of coeliac disease, it is stated that if $\operatorname{IgA}$ anti-tTG exceeds 10 times the upper limit of normal in patients with a clinical suspicion of coeliac disease, diagnosis of coeliac disease is possible by performing further other laboratory tests (endomysial antibodies and HLA typing) instead of duodenal biopsies. An important component of the disease is the intraepithelial lymphocyte that might become clonally expanded in refractory sprue and enteropathy associated T-cell lymphoma ${ }^{10}$

The treatment for coeliac disease is the complete and life-long removal of gluten containing foods from the diet. This should result in the resolution of the inflammation and restoration of the inner lining of the small bowel. Medications to treat conditions such as anaemia and nutrient deficiencies Iron, folate, vit- $\mathrm{B}_{12}$, calcium may be required. Dietary adherence can be monitored by serial tests for antibodies EMA and TTG. Patients should have pneumococcal vaccinations (because of splenic atrophy) once every 5 years. ${ }^{11} \mathrm{~A}$ determination of bone mineral density to asses for osteoporosis is recommended. CD leads to an increased risk of both adenocarcinoma (small intestine) and lymphoma (enteropathy associated T-cell lymphoma), ulcerative jejunitis and stricturing.

\section{Conclusion:}

In conclusion it can be said that, Coeliac Disease is often difficult to diagnose due to its non-specific symptoms and the long period of onset. Diagnosis is based traditionally on symptoms, positive serology and characteristic histo- logical changes. Among these, biopsy remains the gold standard for establishing the diagnosis. There is compelling evidence that treatment of symptomatic Coeliac Disease results in substantial improvement in nutritional parameters. Compliance with life-long gluten free diet is likely protective against the development of non-Hodgkin's lymphoma and Dermatitis herpetiformis.

\section{Reference:}

1. Green, PHR, Cellier, C. Celiac disease. N Engl J Med. 2007; 357:1731-43.

2. Fasano A, Catassi C. Celiac Disease. N Engl J Med. 2012; 367: 2419-26.

3. Binder HJ. Disorders of absorption. In Longo DL, Kasper DL, Jameson JL, Fauci AS, Hauser SL, Loscalzo J, editors. Harrison's Principles of Internal Medicine. 18th ed. New York: The McGraw-Hill Companies Inc. 2469-2471.

4. McQuaid KR, Diseases of the Small Intestine. In McPhee SJ; Papadakis MA; editors. Current Medical Diagnosis and Treatment. 51 st ed. New York: The McGraw-Hill Companies, Inc; 2012. 603-605.

5. Palmer KR Penman ID. Disorders causing malabsorbtion. In Colledge NR; Walker BR; Ralston SH; editors. Davidson's Principles and Practice of Medicine. 21st ed. London: Elsevier Limited 2010. 879-881.

6. Chen CS, Cumbler EU, Triebling AT. Coagulopathy Due to Celiac Disease Presenting as Intravascular Hemorrhage. J Gen Intern Med. 2007; 22(11): 1608-12.

7. Publications.nice.org.uk/coeliac-disease-CG86/guidance. [Online]. 2009 [cited 2013 October 26].

8. Revised criteria for diagnosis of coeliac disease. Report of working Group of European Society of Paediatric Gastroenterology and nutrition. Arch Dis Child. 1990; 65: 909-911.

9. Husby S, Koletzko S, Korponay-Szabo I. European Society for Pediatric Gastroenterology, Hepatology, and Nutrition Guidelines for the diagnosis of coeliac disease. J Pediatr Gastroenterol Nutr. 2012; 54: 136-160.

10. Green PH, Jabri B. Celiac Lancet rev 2003. The Lancet. 2003; 362: 383-91.

11. Fairclough P, Silk D. Disorders of the small intestine causing malabsorption. In Kumar P, Clark M, editors. Kumar \& Clark's Clinical Medicine. 7th ed. London: Elsevier Limited; 2009. 277-80. 